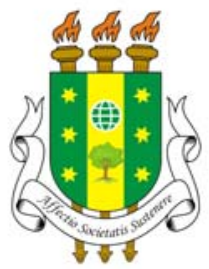

educationis

Journal homepage:

www.arvore.org.br/seer

\section{EDUCAÇÃO PARA O TRÂNSITO SOB A ÉGIDE DA CIDADANIA NO AMBIENTE ESCOLAR}

\section{RESUMO}

Este estudo tem como objetivo apresentar a importância da educação para o trânsito nas escolas através da reflexão sobre os possíveis caminhos que enfatizam essa importância. Pois, diante dos problemas conflituosos em nossa sociedade, se faz necessário uma reflexão no comportamento, para que as gerações futuras não cometam os mesmos erros da geração atual. Falar de educação para o trânsito não é só citar leis e regras, mas também é falar de uma educação na qual se aprende valores que tornem uma sociedade harmônica, sustentável e, sobretudo, é um exercício da democracia e da cidadania no espaço público. Assim, pretende-se explanar o tema educação para o transito numa abordagem transversal, objetivando favorecer momentos de análise e de reflexões sobre a realidade, compreendendo o quanto é importante, na práxis educativa, uma relação entre aprender sobre a realidade e aprender a partir da realidade.

PALAVRAS-CHAVE: Educação; Trânsito; Âmbito Escolar; Interdisciplinaridade; Cidadania.

\section{TRAFFIC EDUCATION UNDER THE AEGIS OF CITIZENSHIP IN THE SCHOOL ENVIRONMENT}

\section{ABSTRACT}

This study aims to present the importance of traffic education in schools through reflection on the possible ways that emphasize its importance. Well, given the conflicting problems in our society, it is necessary to reflect on behavior so that future generations will not make the same mistakes of the current generation. Speaking of traffic education is not only cite laws and rules, but is also talk of an education in which we learn values that make a society harmonious, sustainable and above all, is an exercise of democracy and citizenship in the public space. Thus, it is intended to explain the subject of education for transit in a transversal approach, aiming to promote moments of analysis and reflection about reality, realizing how important it is, in educational practice, learn about a relationship between reality and learn from reality.

KEYWORDS: Education; Traffic; Scope School; Interdisciplinary; Citizenship.
Educationis, Aquidabã, v.1, n.1, Ago, Set, Out, Nov, Dez 2012, Jan 2013.

\section{ISSN 2318-3047}

\section{SECTION: Articles}

TOPIC: Políticas Públicas na Educação

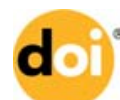

DOI: 10.6008/ESS2318-3047.2013.001.0001

\section{Alana Danielly Vasconcelos} Universidade Federal de Sergipe, Brasil http://lattes.cnpq.br/9144930400445544 alana.vasconcelos06@gmail.com

Received: 12/09/2012

Approved: 05/01/2013

Reviewed anonymously in the process of blind peer

\section{Referencing this:}

VASCONCELOS, A. D.. Educação para o trânsito sob a égide da cidadania no ambiente escolar. Educationis, Aquidabã, v.1, n.1, p.6-16, 2013. DOI: http://dx.doi.org/10.6008/ESS23183047.2013.001.0001 


\section{INTRODUÇÃO}

A educação proporciona a formação do ser humano para que ele saiba viver em sociedade, onde, pretende-se criar uma consciência crítica nos indivíduos fazendo com que os mesmos saibam conviver em coletividade, conhecendo e exercendo seus direitos e deveres, garantindo assim uma convivência harmônica, à luz da cidadania.

Educar é um meio de construir e reconstruir valores e normas que dignificam os indivíduos e os tornam mais humanos. "Numa educação ética, é preciso resgatar e incorporar os valores solidariedade, de fraternidade, de respeito às diferenças de crenças, culturas e conhecimentos, de respeito ao meio ambiente e aos direitos humanos" (SIEGEL, 2005, p.41). Assim, surge à educação voltada para a cidadania, que pretende fazer de cada pessoa um agente de transformação, onde, as pessoas se formam não só para o mercado de trabalho, mas para ser um cidadão, conhecedor dos seus direitos e deveres e praticantes assíduos dos valores éticos que prezam para um bom convívio em sociedade.

Pode-se dizer então, que, ser cidadão é perceber que fazemos parte do mundo. Onde, temos consciência que nossa postura e escolhas realizada diante da vida afetam não só a nós mesmos, mas também a vida de outras pessoas, da sociedade. Assim como as atitudes das outras pessoas podem nos afetar. Isso ocorre claramente no trânsito, a exemplo dos acidentes, quando uma infração é cometida por um indivíduo, a mesma pode afetar gravemente outros indivíduos que ali se encontrarem por perto, ou seja, uma ação apresenta vários resultados.

Devido a isso, a educação para o trânsito surge como uma saída emergencial de sensibilizar e conscientizar os indivíduos a respeitarem as leis de trânsito que existem para assegurar uma convivência harmônica entre as pessoas ao transitarem. Propondo uma conscientização das responsabilidades individuais de cada um no exercício de sua cidadania.

Considerando que os acidentes no trânsito são o segundo maior problema de saúde pública, perdendo para causas internas como doenças cardiovasculares e o câncer, apresentando 350 mil pessoas como vítimas de acidentes e que destes 40 mil são fatais (BRASIL, 2001). governo gasta mais de 10 bilhões de reais na recuperação de acidentados e indenizados. Esses índices apresentam uma das principais causas de morte prematura da população economicamente ativa. Mas apesar da ocorrência grande parte delas é previsível, ou seja, uma consequência causada por uma ação de irresponsabilidade e, por isso, se torna evitáveis.

Os acidentes ocorrem por diversos fatores, tais como: condições de automóveis e estradas, mas o fator dominante é o homem por imprudência e descumprimento do código de trânsito, ou pelo simples fato da sociedade atual está preocupada em competir para progredir, associando a competição a uma forma de progresso. Mas, quando leveda ao trânsito geram-se conflitos e falta de respeito. Dessa forma, se pensa em um ensino para desenvolver uma disciplina de colaboração a ser aplicada no âmbito da vivência social, formando uma nova mentalidade para o comportamento do homem no trânsito. 
A educação vista por esse ângulo, se volta a uma preocupação em tornar as convivências no trânsito mais humanizadas, para que assim, os indivíduos passem a ter um melhor comportamento perante seu semelhante e com o mundo no qual ele vive.

A educação para o trânsito deve-se relacionar com a prática de dirigir com segurança reduzindo a possibilidade de ser envolvido em acidentes. É preciso assim insistir em educação para o trânsito o ano inteiro, equipando os postos policiais com materiais educativos. Sendo assim a situação do trânsito é um problema de educação. Biavati (2010a), nos diz que:

Em nossa sociedade, transitar é um exercício permanente de transgressão das regras de circulação no espaço público. Inventamos a infração "do bem", uma forma "inocente" de submeter à norma às conveniências momentâneas de nossos interesses individuais.

O assunto é muito amplo e isso torna a sua delimitação uma necessidade, para o presente artigo. Diante de questões norteadoras que serão citadas ao longo do texto, ir-se-á perceber que o mais importante seria priorizar a acessibilidade e a mobilidade as pessoas e não aos veículos.

O arrefecimento do ser humano frente ao realce que é dado ao meio de transporte pode gerar conflitos. Porém, não é este o único fator que gera debates. Os pontos de vista das pessoas se divergem bastante, cada indivíduo possui sua particularidade, mas, mesmo com as diferenças devemos aprender a conviver com as mesmas, pois o que ocorre hoje é a falta de compreensão entre gerações, como nos traz (LARAIA, 2008, p.98):

São essas aparentemente pequenas mudanças que cavam o fosso entre as gerações, que faz com que os pais não se reconheçam nos filhos e estes se surpreendam com a caretice de seus progenitores, incapazes de reconhecer que a cultura está sempre mudando.

Justifica-se, então, a escolha do tema como uma decorrência da atenção com que as políticas públicas brasileiras para o trânsito começam a olhar para a educação no trânsito como um recurso fundamental para uma mobilidade urbana sustentável e como um caminho para transformação da visão da sociedade que hoje, grita por socorro diante das perdas matérias e pessoas que vem se perdendo pela falta de educação das pessoas que fazem parte desta sociedade, para que assim:

Gostaríamos de ver no trânsito uma expressão de cidadania, um modo de partilhamento do espaço das vias públicas, ordenado por regras comuns e impessoais. Mais do que uma necessidade vital individual, transitar seria um exercício cotidiano de solidariedade, gentileza e, sobretudo, respeito à integridade de cada pessoa, especialmente daquelas cujos deslocamentos as colocam em posição mais frágil na cidade - os pedestres (BIAVATI, 2010a).

O presente artigo aborda a possibilidade de adoção, em todos os níveis de ensino, de um currículo interdisciplinar sobre segurança no transito tornando-se necessário um planejamento e ações coordenadas entre órgãos e entidades do Sistema Nacional de Transito e de Educação, da União, dos Estados e dos Municípios que, num esforço conjunto, devem assumir a implantação de projetos voltados para a prevenção e redução de acidentes. Inserir o tema trânsito na rede escolar, numa abordagem transversal, não de forma superficial, mas como parte integrante das áreas curriculares, transformando-se em um elemento constante de análises, reflexões e debates, 
objetivando possibilitar o desenvolvimento de valores, de posturas e de atitudes corretas, facilitando o convívio social.

\section{DISCUSSÃO TEÓRICA}

\section{Educação para o Trânsito no Contexto Social}

Devemos chamar a atenção para as crescentes notícias que vemos todos os dias nos jornais televisivos, nos rádios, na internet sobre as inúmeras mortes que vem ocorrendo no trânsito. Mortes essas que muitas das vezes são causadas por imprudências/irresponsabilidades ou descumprimento de atividades da gestão pública nos serviços prestados a sociedade.

Apontar o culpado é mais fácil do que reconhecer e admitir o próprio erro. As mortes ocasionadas no trânsito causam sequelas graves e mortais. Não se pode jogar a culpa no governo, nem no individuo porque ele é jovem e considerado "irresponsável", a culpa é de todos nós, nós cidadãos que pagamos nossas contas e não sabemos exigir nossos direitos ou muito pior, não cumprimos as leis que regem em nossa sociedade para garantir uma harmonização no nosso ambiente social.

Segundo (BIAVATI, 2010b), não fomos capazes de conter esse avanço de violência no trânsito em nosso país. Preocupamo-nos com os responsáveis e nos acomodamos em nossas particularidades sem agir, sem nada fazer.

O início da vida escolar de uma criança é um estágio em que ela assimila o que seu educador the ensina. A inserção da educação no trânsito nas escolas é formar crianças que futuramente serão os condutores da nova geração. Muitos adultos colocam a culpa nos jovens e ainda dizem que a linguagem jovial é difícil de entender e trabalhar. Ora, os jovens de hoje não são os mesmo jovens da década de 30 ou 60, os jovens de hoje são jovens que foram prestigiados, pois, possuem grandes poderes nas mãos como a mídia e a internet.

Daí se pode questionar: o porquê de tanta violência no trânsito? Realmente precisa de educação de trânsito? Ultrapassar o sinal vermelho é falta de educação? Jogar papel pela Janela do carro, não é falta de educação? A escola faria parte desse contexto? Como se pode notar os questionamentos nos dão uma visão ampla e complexa. Para que se entenda o trânsito se faz necessário saber o que é trânsito, e de acordo com o Código de Trânsito Brasileiro:

Art.1 $1^{\circ} \S 1^{\circ}$ considera-se trânsito a utilização das vias por pessoas, veículos e animais, isolados ou em pequenos grupos, conduzidos ou não, para fins de circulação, parada, estacionamento e operação de carga ou descarga (BRASIL, 2006, p.9).

Válido ressaltar que trânsito não é só carro, motorista, acidente. Transitar é executar o seu direito de ir e vir, é questão de cidadania, de valores, valores esses que aprendemos na estância de nossas vidas seja na escola ou na família. 
A educação, para uns é um processo de socialização do indivíduo, para outros vai além de uma socialização, sendo considerada como base, o alicerce para se viver em sociedade, respeitando regras e repassando valores. No mais, quando se fala em educar, se fala em orientar, guiar os indivíduos para respeitarem regras ditadas por uma ideologia, regras essas que servem para facilitar o convívio em grupos sociais para que assim se possa viver em harmonia.

Já para Freire (1996), a educação está preocupada em formar o indivíduo para o trabalho e para ser cidadão, deve ser contínua até os âmbitos da Universidade, onde, o indivíduo é preparado para ser o educador e não mais o educando, é como nos traz em seu livro Pedagogia da Autonomia, onde, o autor nos diz que educar é libertar, é construir, levar o indivíduo a ser crítico. Com tudo isso se houve uma preocupação na reformulação na maneira de ensinar e consequentemente na forma de elaboração dos currículos escolares, onde a educação para o trânsito foi posta como um tema transversal.

Dessa forma, é de grande importância que o currículo seja democrático, levando principalmente o conhecimento necessário para a formação do indivíduo, não só para o mercado de trabalho, mas também se preocupando em formar cidadãos. Tendo assim o currículo como não sendo conteúdos prontos que serão repassados ao aluno, mas como

[...] uma construção e seleção de conhecimentos e práticas produzidas em contextos concretos e em dinâmicas sociais, políticas e culturais, intelectuais e pedagógicas. Conhecimentos e práticas expostos às novas dinâmicas e reinterpretados em cada contexto histórico. (ARROYO, 2007)

Chegando assim a conclusão de que a educação é o processo de socialização onde se prepara o indivíduo para que o mesmo possa ser crítico, conhecendo seus direitos e deveres, produzindo conhecimentos interdisciplinares que the possibilitem interagir com a grande diversidade que existe na sociedade em todos os aspectos, sejam eles políticos, culturais, sociais.

A tarefa de educar uma criança não compete somente à escola, ou a família, cada uma tem papel fundamental na formação educacional da criança, pois os valores repassados são diferentes e na maioria das vezes se completam. Tais valores são fundamentais para que se obtenha uma convivência em sociedade harmônica, onde se convive com a diferença, porém respeitando-a, exemplos de valores são: o respeito, a cidadania, a solidariedade, a união, a ética, a justiça, a igualdade entre outros.

É bem verdade que no mundo de hoje as pessoas estão menos "civilizadas", ou, podemos dizer menos educadas, pois, não sabem mais a diferença entre um lixeiro e uma calçada, sabem o Código de Trânsito, mas passam no sinal vermelho, as boas maneiras não moram mais em casa quem dirá na rua, na escola, no trabalho. A escola é um espaço de convivência onde cada criança/adolescente passa a maior parte de suas vidas. Nela, aprendem a conviver com as diferenças e a conviver em grupo para que assim possam ser exemplos na sociedade a fora. A escola como espaço de educação continuada e de socialização, tem um papel fundamental na formação dos indivíduos para que os mesmos saibam viver nas relações sociais respeitando seus limites e o espaço do outro. 
Educar para o trânsito é criar uma geração de indivíduos comprometidos com a vida e a segurança. Pensando nisso se observa a necessidade de se levar a educação para o trânsito às escolas com o intuito de criar uma consciência responsável nos sujeitos que se encontram em formação intelectual. A valorização da vida, os valores como o respeito, a solidariedade, a ética, a responsabilidade, a cidadania, a segurança, a igualdade, são valores que devem ser trabalhados dentro e fora da sala de aula já que vivemos em sociedade e devemos assim caminhar sempre olhando o coletivo e deixando de lado "o ser individual".

Segundo a Lei de no 9.503: desde 1998, o Código de Trânsito Brasileiro determinou (Art. 76) que a Educação para o Trânsito é obrigatória nas escolas, em todos os níveis, desde a educação infantil até as universidades. Onde, as escolas teriam um currículo interdisciplinar e a educação para o trânsito seria promovida através de palestras, cultivando a cidadania, discussões, campanhas, promovendo aos alunos um conteúdo sistemático referente aos temas de trânsito como atividades de humanização que precisam ser cumpridas e respeitadas por qualquer cidadão.

A educação que socializa o indivíduo o deixa apto para perceber que a sua qualidade de vida no ambiente social dependerá das suas atitudes. Seja em casa, na rua ou na escola cada ser humano tem papel fundamental na organização e na qualidade que terá a sua sociedade.

Para que se tenha uma educação de qualidade é necessária uma formação sociável e de forma continuada. E a escola é o ambiente que possibilita aos educandos a organizar os conteúdos que levam ao aprendizado, construindo e reconstruindo os conceitos básicos como: ética e cidadania, refletindo em mudança de postura diante do trânsito tornando-o um cidadão consciente e participativo.

É bem verdade que segundo o Código de Trânsito Brasileiro cada município deve ter a sua coordenadoria de educação para o trânsito e que as mesmas desenvolvam atividades educativas voltadas para a população, como traz o art.74. $\$ 1^{\circ}$ É obrigatória existência de coordenação educacional em cada órgão ou entidade componente do Sistema Nacional de Trânsito (BRASIL, 2006, p.35).

Apesar do Código Nacional de Trânsito ordenar, como toda lei elaborada para ser cumprida. As coordenadorias de educação para o trânsito encontram dificuldades na realização de campanhas educativas por falta de verba. Infelizmente, a Educação no Brasil está como sempre esteve preocupada com quantidade e não com qualidade.

Educar para o Trânsito possibilita interferir nessa situação caótica em que se encontram os indivíduos durante seu trajeto diário, procurando desenvolver ações geradoras de mais segurança e possibilitando uma melhor qualidade de vida, com atitudes coletivas e cooperativas no trânsito.

Um ambiente educacional deve propiciar a confrontação de pontos de vista divergentes, de concepções diferentes a respeito de uma mesma situação ou tarefa. Pensando nisso, foi que em 21 de setembro com a Lei de no 5.108 que a Educação de Trânsito passou a ser mencionado no Código Nacional de Trânsito, mas precisamente no capítulo VI. Desde então, os órgãos de 
trânsito passaram a ter, obrigatoriamente, um setor específico para tratar as questões educacionais de trânsito, as CET's (Coordenadorias de Educação para o Trânsito), como podemos ver no Capítulo VI, Art. 74,

$\S 1^{0}$ É obrigatória a existência de coordenação educacional em cada órgão ou entidade componente do Sistema Nacional de Trânsito.§ $2^{\circ}$ Os órgãos ou entidades executivos de trânsito deverão promover, dentro de sua estrutura organizacional ou mediante convênio, o funcionamento de Escolas Públicas de Trânsito, nos moldes e padrões estabelecidos pelo CONTRAN. (BRASIL, 2006).

Ainda de acordo com o CTB, a educação para o trânsito deve ser promovida em todas as esferas escolares, sejam elas municipais, estaduais ou federais. Como se pode notar no Art. 76,

A educação para o trânsito será promovida na pré-escola e nas escolas de $1^{\circ}, 2^{\circ} \mathrm{e}$ $3^{\circ}$ graus, por meio de planejamento e ações coordenadas entre os órgãos e entidades do Sistema Nacional de Trânsito e de Educação, da União, dos Estados, do Distrito Federal e dos Municípios, nas respectivas áreas de atuação. (BRASIL, 2006).

Para a finalidade prevista neste artigo, o Ministério da Educação e do Desporto, mediante proposta do CONTRAN ${ }^{1}$ e do Conselho de Reitores das Universidades Brasileiras, diretamente ou mediante convênio, e de acordo com as normas bases do CONTRAN, deve promover,

I - a adoção, em todos os níveis de ensino, de um currículo interdisciplinar com conteúdo programático sobre segurança de trânsito;

II - a adoção de conteúdos relativos à educação para o trânsito nas escolas de formação para o magistério e o treinamento de professores e multiplicadores;

III - a criação de corpos técnicos interprofissionais para levantamento e análise de dados estatísticos relativos ao trânsito;

IV - a elaboração de planos de redução de acidentes de trânsito junto aos núcleos interdisciplinares universitários de trânsito, com vistas à integração universidadessociedade na área de trânsito. (BRASIL, 2006)

A partir disso, a educação para o trânsito foi inserida nos Parâmetros Curriculares Nacionais ou PCN como atividade pertencente aos temas transversais, porém como a educação para o trânsito é considerada tema transversal, a mesma será inserida nos conteúdos programáticos de maneira interdisciplinar e de acordo com a realidade local. Como se pode notar a seguir,

(...) Tomando-se como exemplo o caso do trânsito, vê-se que, embora esse seja um problema que atinge uma parcela significativa da população, é um tema que ganha significado principalmente nos centros urbanos, onde o trânsito tem sido fonte de intrincadas questões de natureza extremamente diversa. Pense-se, por exemplo, no direito ao transporte associado à qualidade de vida e à qualidade do meio ambiente; ou o desrespeito às regras de trânsito e a segurança de motoristas e pedestres (o trânsito brasileiro é um dos que, no mundo, causa maior número de mortes). Assim, visto de forma ampla, o tema trânsito remete à reflexão sobre as características de modos de vida e relações sociais (BRASIL, 1997, p.35).

Levando em consideração o texto da Política Nacional de Trânsito - PNT (BRASIL, 2004), "a educação para o trânsito tem como mola mestra a disseminação de informações e a participação da população na resolução de problemas e só é considerada eficaz na medida em que a população se conscientiza do seu papel como protagonista no trânsito e modifica

\footnotetext{
${ }^{1}$ Conselho Nacional de Trânsito. Órgão máximo normativo, consultivo e coordenador da política nacional de trânsito.
} 
comportamentos indevidos" (BRASIL, 2004, p.15), ou seja, o processo educativo só ocorre quando o indivíduo assimila o conhecimento e o coloca em prática apresentando uma nova postura, um novo comportamento frente à sociedade.

Promover educação para o trânsito de acordo com (MANTOVANI, 2011) significa discutir questões sobre: o exercício de cidadania; mobilidade, acessibilidade, o compartilhamento do espaço, o meio ambiente e a história de cada local. Tudo isso permite garantir o direito de ir e vir de todo cidadão. Porém, segundo a autora, é válido ressaltar a necessidade de estabelecer a união entre a ética e a cidadania, para promover uma mudança de comportamento da sociedade, com relação ao contexto social trânsito do qual fazemos parte.

A educação voltada para a formação cidadã pretende fazer de cada indivíduo um agente de transformação. Segundo (GALVÃO, 2011), isso exige uma reflexão que possibilite compreender as raízes históricas da situação de miséria e exclusão em que vive boa parte da população. De acordo com o autor, "a formação política, que tem no universo escolar um espaço privilegiado, deve propor caminhos para mudar as situações de opressão".

Ainda com (GALVÃO, 2011), "muito embora outros segmentos participem dessa formação", como a exemplo da família ou os meios de comunicação, ambos exemplos postos pelo autor, "não haverá democracia substancial se inexistir essa responsabilidade propiciada", e principalmente, pelo ambiente escolar, ressalta o mesmo. A ideia de educação deve estar intimamente ligada à de liberdade, cidadania e democracia. Segundo o mesmo autor, "a educação não pode preparar nada para a democracia a não ser que a mesma também seja democrática".

A democracia não se refere só à ordem do poder público do Estado, mas devem existir em todas as relações sociais, econômicas, políticas e culturais. Começa na relação interindividual, passa pela família, a escola e culmina no Estado. Uma sociedade democrática é aquela que vai conseguindo democratizar todas as suas instituições e práticas. (BOBBIO, 2002)

O trânsito é um fenômeno social, que envolve vidas humanas num determinado contexto sócio histórico. Desta forma, entendo que a educação está envolvida em todo e qualquer processo de socialização, construção e transformação da realidade. Percebo que, a educação para o trânsito é uma necessidade de primeira ordem e uma prática pedagógica que vai além de uma mera aprendizagem de comportamentos e hábitos; a mesma propicia mudanças de atitudes frente à complexidade do Trânsito e à forma de valorização da vida.

Para que ocorra isso, a educação para o trânsito deve lançar mão da transdisciplinaridade ${ }^{2}$, com o objetivo de fazer conexões entre os conteúdos programáticos com as questões de trânsito, ampliando dessa forma os campos de conhecimento e possibilitando o desenvolvimento e enriquecimento dos conteúdos trabalhados. Ainda, devendo potencializar a formação do aluno como pessoa consciente, responsável, crítica, dinâmica, solidária e acima de

\footnotetext{
2 "A transdisciplinaridade, como o prefixo "trans" indica, diz respeito àquilo que está ao mesmo tempo entre as disciplinas, através das diferentes disciplinas e além de qualquer disciplina. Seu objetivo é a compreensão do mundo presente, para o qual um dos imperativos é a unidade do conhecimento" (NICOLESCU, 1999).
} 
tudo cidadão; indivíduo que seja capaz de fazer opções livres em sua ação individual, tornando-se atuante na sociedade em que habita, tendo a cidadania como ponto de chegada.

No sentido dado, a educação para o trânsito implicaria em examinar a necessidade da inclusão curricular e criação de elementos epistemológicos na perspectiva do caráter que deve ter o conhecimento no processo educativo.

Ainda, segundo (BIAVATI, 2010b), não se pode imaginar vida social sem trânsito, pois, transitamos a toda hora. Porém transitar se tornou algo muito perigoso, explica ele:

Existem regras, é claro - elas deveriam regular o conflito, garantindo segurança para todos. Esse é o sentido do Código de Trânsito. As regras, porém, não são suficientes para mudar a realidade cotidiana das disputas no espaço público. $\mathrm{O}$ acidente de trânsito que contamos aos milhares é uma decorrência desses conflitos e, por isso mesmo, raramente acidente é um "acidente".

Biavati trás uma longa bagagem de experienciais, e de acordo com ele a sociedade está passando por muitos conflitos. Tais conflitos são problemas que até hoje não foram resolvidos, aos quais, só trazem dor de cabeça para a população. Esses conflitos geralmente são causados pela falta de estrutura de estado, por falta de dinheiro, e o pior por falta de conhecimento da população de conhecer os seus direitos. Hoje, tem-se problemas na educação, na saúde, na economia, etc. como resolver esses problemas?; O ditado é muito antigo: "cada um faz a sua parte", porque assim, poderemos chegar um dia a sonhar com uma educação no trânsito em que:

\begin{abstract}
Gostaríamos de ver no trânsito uma expressão de cidadania, um modo de partilhamento do espaço das vias públicas, ordenado por regras comuns e impessoais. Mais do que uma necessidade vital individual, transitar seria um exercício cotidiano de solidariedade, gentileza e, sobretudo, respeito à integridade de cada pessoa, especialmente daquelas cujos deslocamentos as colocam em posição mais frágil na cidade - os pedestres. (BIAVATI, 2010a)
\end{abstract}

O sonho faz parte da vida, o que seria de cada ser humano se não sonhasse?!Pois, através deles temos ideias que queremos alcançar. A educação de cada indivíduo dependerá da sua bagagem, por isso a importância de se formar de cedo as crianças, para que as mesmas possuindo uma educação formal continuada sejam capazes de não cometer os mesmos erros da sociedade de hoje. A vida é o maior bem que se tem, mas, infelizmente no ambiente social que nos encontramos ela é comparada a algo "sem valor".

O problema maior da sociedade contemporânea é o individualismo dos homens,

O problema começa quando milhões de habitantes fazem a mesma coisa simultaneamente. Quando falha o ordenamento, prevalece à força dos interesses particulares e, principalmente, sabota-se a previsibilidade das ações no trânsito e sem previsibilidade não há trânsito seguro (BIAVATI, 2010a)

A partir do momento em que o homem passa a respeitar as regras, ele passa a valorizar a si mesmo e a respeitar o espaço do outro, até porque as regras foram feitas/elaboradas com o objetivo de trazer um convívio harmonioso entre as pessoas. Assim, diante dos dados, nota-se que o próprio sistema de trânsito precisa de mudança, como também a educação, a saúde e outros, precisam de melhorias reais para formar e dar condições de aprendizagem e qualidade de vida as pessoas. Mas, independentemente de falhas nas estruturas sociais, cabe a cada cidadão 
fazer a sua parte, exigir seus direitos à medida que os cumpre. Os mais velhos devem dar bons exemplos aos mais novos, pois, eles serão os velhos do amanhã.

\section{CONSIDERAÇÕES FINAIS}

Sabendo que trânsito não corresponde só a carros, que trânsito é o ato de transitar pelas ruas e avenidas de uma cidade, pode-se notar que o mesmo faz parte do dia - a- dia de todo e qualquer ser humano. Para viver em sociedade recebemos regras, essas que regem todo o sistema social para garantir que tenhamos uma boa convivência entre nós (seres socializados).

Apesar de saber da existência de regras, nem todas as pessoas as respeitam, seja por falta de conhecimento das leis ou por falta de educação. Mas, essa falta de conhecimento das leis ou essa falta de educação quando levada ao trânsito, causa vítimas fatais, vítimas essas que na maioria das vezes são as próprias culpadas ou só estavam no lugar errado e na hora errada.

Mesmo com dificuldades financeiras, as Coordenadorias de Educação para o Trânsito (CET) se empenham em campanhas educativas nas ruas e escolas, com o objetivo de sensibilizar a sociedade para com o valor da "vida". Porém, as Coordenadorias de Educação para o Trânsito (CET) encontram dificuldades para manter as campanhas de uma forma continuada. A partir daí se pensa em inserir a educação para o trânsito nas escolas, visto que as mesmas têm o papel de formar cidadãos críticos, que sejam preparados para o trabalho e tenham uma consciência voltada para o viver em igualdade.

É de competência das escolas promoverem um currículo diverso e dinâmico para seus alunos. Elaborando assim, conteúdos voltados para os acontecimentos do dia-a-dia, levando para seu público, temas geradores de opiniões, para que se tornem seres críticos.

Mesmo com tantos problemas em nosso país, devemos nos preocupar com a crescente quantidade de vítimas de trânsito. Pode-se até arriscar que o trânsito será considerado como uma das maiores epidemias que causará grande mau à sociedade e ao meio ambiente. Além de ajudar no crescimento do aquecimento global, com a emissão de gases pelos carros, transitar pelas vias daqui a alguns anos será quase impossível.

O trabalho educativo só terá resultado quando for elaborado continuamente. Educar para o trânsito é formar cidadãos conscientes e responsáveis pela vida e pela segurança. Trânsito é o direito de ir e vir e fazer valer esse direito é dever de todo e qualquer cidadão de bem.

Assim, com a inserção da educação para o trânsito nas escolas, se terá uma garantia de que a formação será continuada, além do estreitamento de laços entre a escola e a comunidade. Preparando a geração mais nova para que a mesma não cometa os erros da geração de hoje, pois, eles serão os representantes no amanhã.

\section{REFERÊNCIAS}

ARROYO, M. G.. Indagações sobre currículo: educandos e educadores: seus direitos e o currículo. Brasília: SEB/MEC, 2007. 
BIAVATI, E.. Transgressão. Disponível: <http://biavati.wordpress.com/2009/03/13/transgressao>. Acesso: 6 ago 2010a.

BIAVATI, E.. Livro. Disponível: <http://biavati.wordpress.com/livro>. Acesso: 6 ago 2010b.

BRASIL. Parâmetros curriculares nacionais: introdução aos parâmetros curriculares. Brasília: MEC/SEF, 1997.

BRASIL. Ministério da Saúde do Brasil. Organização Pan-Americana da Saúde no Brasil. Doenças relacionadas ao trabalho: manual de procedimentos para os serviços de saúde. Brasília: Ministério da Saúde do Brasil, 2001.

BRASIL. PNT: Política Nacional de Trânsito. Brasilia: 2004.

BRASIL. Código de Trânsito Brasileiro: instituído pela Lei nº 9.503, de 23-9-97. 2 ed. Brasília: DENATRAN, 2006.

BOBBIO, N.. Teoria geral da política. Rio de Janeiro: Campus, 2002.

FREIRE, P.. Pedagogia da autonomia: saberes necessários à prática educativa. São Paulo: Paz e Terra, 1996.

GALVÃO, R. C. S.. Educação para cidadania: o conhecimento como instrumento político de libertação. Disponível: <http://www.educacional.com.br/articulistas/outrosEducacao_artigo.asp?artigo=artigo0050>. Acesso: 11 dez 2011.

LARAIA, R. B.. Entrevista. Caxambu: FGV, 2008.

MANTOVANI, R.. Educação para o trânsito. Disponível:<http://transitolandia.webs.com/educpotrnsito.htm> . Acesso: 20 nov 2011.

NICOLESCU, B.. Um novo tipo de conhecimento: transdisciplinaridade. In: ENCONTRO CATALISADOR DO CETRANS. Anais. Itatiba: USP, 1999.

SIEGEL, N.. Fundamentos da educação: temas transversais e ética. Indaial: ASSELVI, 2005. 